\title{
Do Bioresorbable Vascular Scaffold Stents Reduce Very Late Stent Thrombosis? A Systematic Review
}

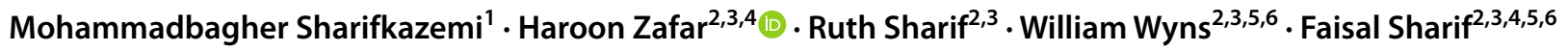

Accepted: 21 February 2022 / Published online: 1 March 2022

(c) The Author(s) 2022

\begin{abstract}
Given the complications caused by stents, especially acute thrombosis, and the late and very late stent thrombosis (VLST) following percutaneous intervention (PCI) in patients, bioresorbable vascular scaffolds (BRSs) have been designed in recent years, so that their absorbance over 3 years can help eliminate the complications of non-absorbable scaffolds in the coronary arteries. Nevertheless, some studies have demonstrated their ineffectiveness or even the increased incidence of short-term and late thrombosis compared to drug-eluting stents (DESs). Studies including cohorts and registry studies as well as clinical trials have been conducted to compare these two types of stents in terms of the incidence of VLST over a period of more than 1 year. The present systematic review study investigates randomized clinical trials conducted over the last 10 years to compare the incidence rates of VLST as a result of BRSs versus DESs. A total of 11 articles were found that had investigated VLST in randomized clinical trials, and the results of two of the articles showed an increase in these complications with BRS. Therefore, until further studies are conducted and more acceptable results are obtained, we recommend that these types of stents only be used in cases where they are required according to the standards.
\end{abstract}

Keywords Very late stent thrombosis · Bioresorbable vascular scaffold · Drug-eluting stent

\section{Introduction}

Because of the high prevalence of coronary atherosclerosis, clinically presenting with chronic or acute symptoms of coronary stenosis, a variety of treatment methods have been proposed in recent years, including percutaneous coronary

This article is part of the Topical Collection on Medicine

Haroon Zafar

haroon.zafar@nuigalway.ie

1 Department of Cardiology, Nemazee Hospital, Shiraz University of Medical Sciences, Shiraz, Iran

2 Lambe Institute for Translational Research, School of Medicine, National University of Ireland Galway, 2nd Floor, Galway, Ireland

3 Cardiovascular Research and Innovation Centre Ireland, National University of Ireland Galway, Galway, Ireland

4 BioInnovate, Galway, Ireland

5 Department of Cardiology, University Hospital Galway, Galway, Ireland

6 CÚRAM-SFI Centre for Research in Medical Devices, Galway, Ireland intervention (PCI) and stent placement, as less invasive method than coronary artery bypass grafting (CABG) [1]. Nevertheless, PCI with stenting is also associated with some complications, including stent thrombosis, which can occur since stent placement until many years after [2]. Very late stent thrombosis (VLST) is defined, by the Academic Research Consortium, as thrombosis that occurs 1 year after stenting [3]; as it can lead to myocardial infarction and even death, anticoagulant therapy, especially dual antiplatelet therapy (DAPT) with aspirin and P2Y12, has been recommended for prevention of VLST [4]; the duration of its administration depends on patients' choice, the stability of the condition, the possibility of hemorrhage, and the stent type used [5, 6].

As the complications of stents have been attributed to its scaffold, the original bare metal stents with metal scaffolding were replaced with modern generation of stents [7]. Drugeluting stent (DES) has been recommended in patients with acute coronary syndrome (ACS) or stable coronary artery disease (CAD), superior to bare metal stents. However, as devices which indwell permanently alter the vasomotor tone and prevent vascular repair, they cause long-term complications, such as vessel caging and rupture, and limit 
the possibility of re-intervention; another scaffold has been recently suggested, bioresorbable vascular scaffolds (BRSs), which theoretically has fewer long-term complications for the arteries due to their absorbability [8]. Yet, some recent studies following-up patients in registries or randomized clinical trials (RCTs) have not shown any significant difference in complication rates of these scaffolds [9]. Considering the uncertainty about complications of these scaffolds, the present study aims to investigate clinical trials conducted on BRSs and the rate of VLST associated with them compared to other stents, and, if possible, answer the question of what factors increase the chances of developing VLST. To this end, the present systematic review examined all the clinical trial studies conducted in the last 10 years.

\section{Methods}

The present systematic review study was designed to investigate the incidence of VLST as the main outcome in patients with BRS insertion compared to those with other stent insertions.

\section{Search Strategy}

Medline and Embase search engines were used to find the relevant studies using the following keywords: bioresorbable, very late, late, long term, thrombosis, stents, and clinical trial. All the RCT studies conducted on humans over the last 10 years (2010 to 2020) and published in English were assessed for this review study. The inclusion criteria were as follows:

1. Randomized clinical trial studies;

2. Studies with a follow-up of at least 50 patients with CAD who had undergone PCI;

3. BRS stents had been used in one of the study groups;

4. The patients were assessed and followed-up with for at least 12 months;

5. DAPT was initiated for the patients following PCI;

6. VLST was assessed as a stent-related complication, defined as thrombosis occurring later than a year after stent insertion.

The study exclusion criteria were as follows:

1. Non-randomized clinical trial studies;

2. Studies conducted only on a specific group of patients with a specific disease, like patients with chronic kidney disease;

3. Study groups not compared in terms of clinical outcome;

4. Lack of definitive diagnosis of thrombosis following stenting;

\section{Non-English articles.}

The main outcome investigated was thrombosis following stenting as well as coronary stent thrombosis heralding death.

\section{Data Collection}

The titles and abstracts of all the studies, retrieved through the initial search, were reviewed by the researchers, and those that met the study's inclusion and exclusion criteria were selected. The selected articles were then reviewed in full. The researchers examined the objectives of the studies, their methods in detail, their assessed outcomes and the methods of obtaining these outcomes, and also their results and method of reporting, and enrolled those that met the study inclusion and exclusion criteria to the study.

\section{Results}

Before the inclusion of clinical trials, a total of 1474 articles were found in the initial search in Medline and Embase, most of which were observational, including case-control or cohort studies. Then, taking clinical trial as the type of study resulted in 241 articles, which were reduced to 65 articles after reviewing the abstracts or entire articles, wherever necessary. The full text of all the 65 articles was assessed, and only those that met the inclusion criteria were selected. All the selected articles were RCTs. For confirming all studies as RCT, websites of clinical trial registries, especially the $\mathrm{NIH}$-affiliated (https://clinicaltrials.gov)/, were reviewed in full, as well. In the next step of the study, 15 studies that had examined thrombosis earlier than 12 months were excluded. In addition, one of the articles was a duplicate, and 11 articles that had investigated stent complications for more than a year were thus included in this study. Two studies have been performed on the same patients, reporting the 2- and 3-year outcomes of patients $[10,11]$. The PRISMA flow diagram of enrollment and exclusion of studies at each step of the study is shown in Fig. 1.

Table 1 presents the details of these studies. All the studies were multi-centered and only the patients were blinded to the study implementation. The frequency of the USA was higher in the ABSORB China study than the other studies, and AIDA and ABSORB III had the largest sample sizes.

Table 2 presents the details of the participating patients. It can be seen that there were no significant differences between the two groups of patients in these studies in terms of age, gender, and risk factors of cardiovascular diseases. The highest mean age and frequency of diabetes pertained to the patients participating in the ABSORB Japan study. The highest frequency of hypertension and hyperlipidemia 

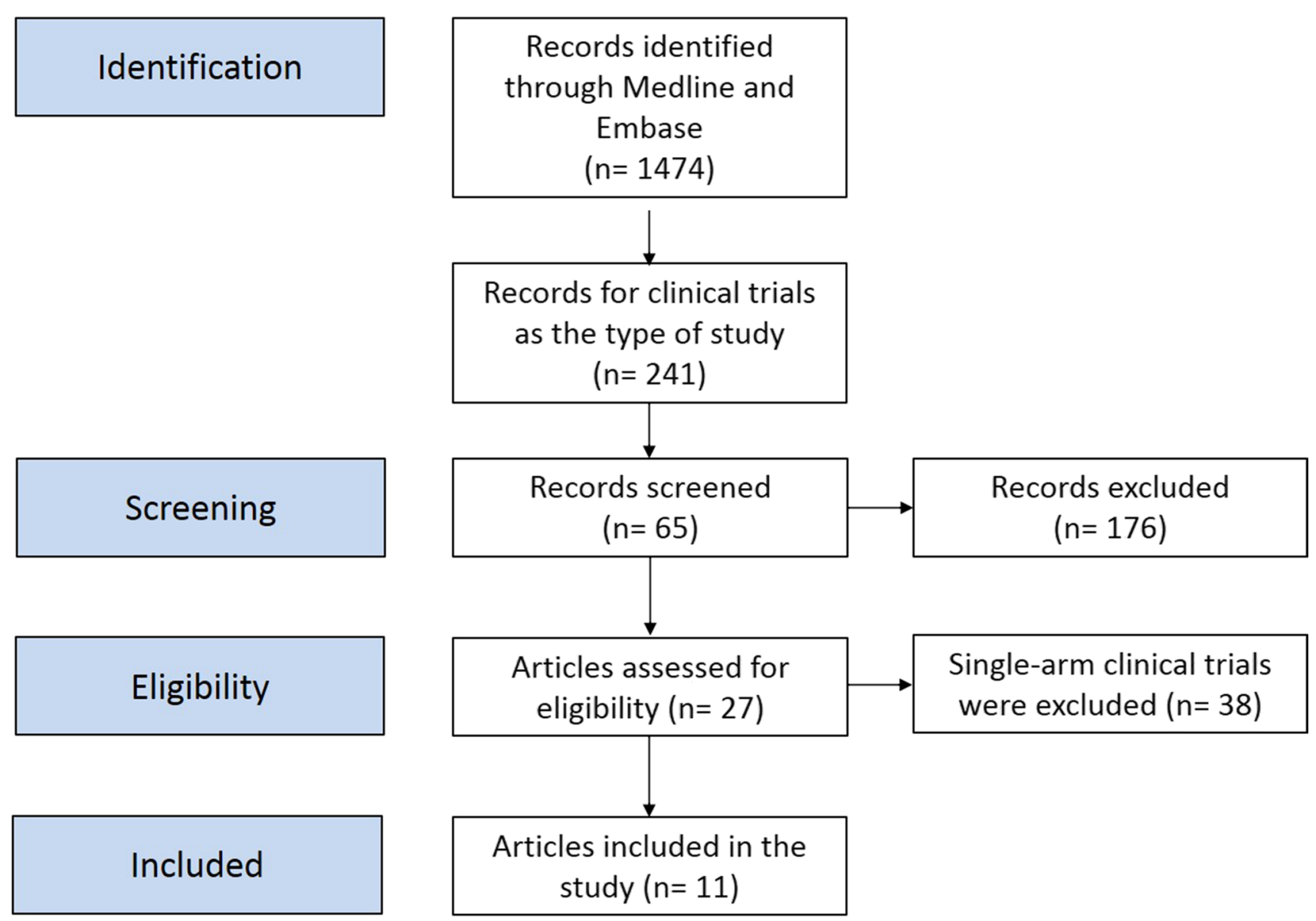

Fig. 1 PRISMA flow diagram

Table 1 The characteristics of the studies included in the systematic review

\begin{tabular}{llll}
\hline Author & Study name & The two trial groups & Blinding \\
\hline Xu B et al. [12] & ABSORB China & BVS vs. CoCr-EES & None (open label) \\
Chevalier B et al. [13] & ABSORB II & ABSORB BVS vs. XIENCE & Single (participants) \\
Kereiakes DJ et al. [14] & ABSORB III & ABSORB BVS vs. XIENCE & Single (participants) \\
Onuma Y et al. [15] & ABSORB Japan & ABSORB BVS vs. XIENCE & Single (participants) \\
Kozuma K et al. [16] & ABSORB Japan & ABSORB BVS vs. XIENCE & Single (participants) \\
Wykrzykowska JJ et al. [17] & AIDA & BVS vs. EES & Single (participants) \\
Kandzari DE et al. [11] & BIOFLOW V & BP SES vs. DP EES & Single (participants) \\
Kandzari DE et al. [10] & BIOFLOW V & BP SES vs. DP EES & Single (participants) \\
Wijns W et al. [18] & CENTURY II & BP SES vs. DP EES & Single (participants) \\
Katagiri Y et al. [19] & TROFI & BVS vs. EES & Single (participants) \\
Wu Y et al. [20] & XINSORB (metallic SES) & XINSORB vs. SES & Single (participants) \\
\hline
\end{tabular}

were observed in the ABSORB III study, and the highest number of currently smoking patients was observed in the TROFI study. Close to $70 \%$ of the patients in all the studies were male.

Table 3 shows the frequency of VLST. The incidence of VLST differed significantly in the 3-year versus the 5-year follow-ups in the ABSORB III, BIOFLOW V, and AIDA studies. VLST was more frequent in the BRS group in the ABSORB III and AIDA studies and also in the DP EES group in the BIOFLOW V study. Antiplatelet therapy was used in about $30 \%$ or less of the cases in all the studies, except in the XINSORB (metallic SES) study. 


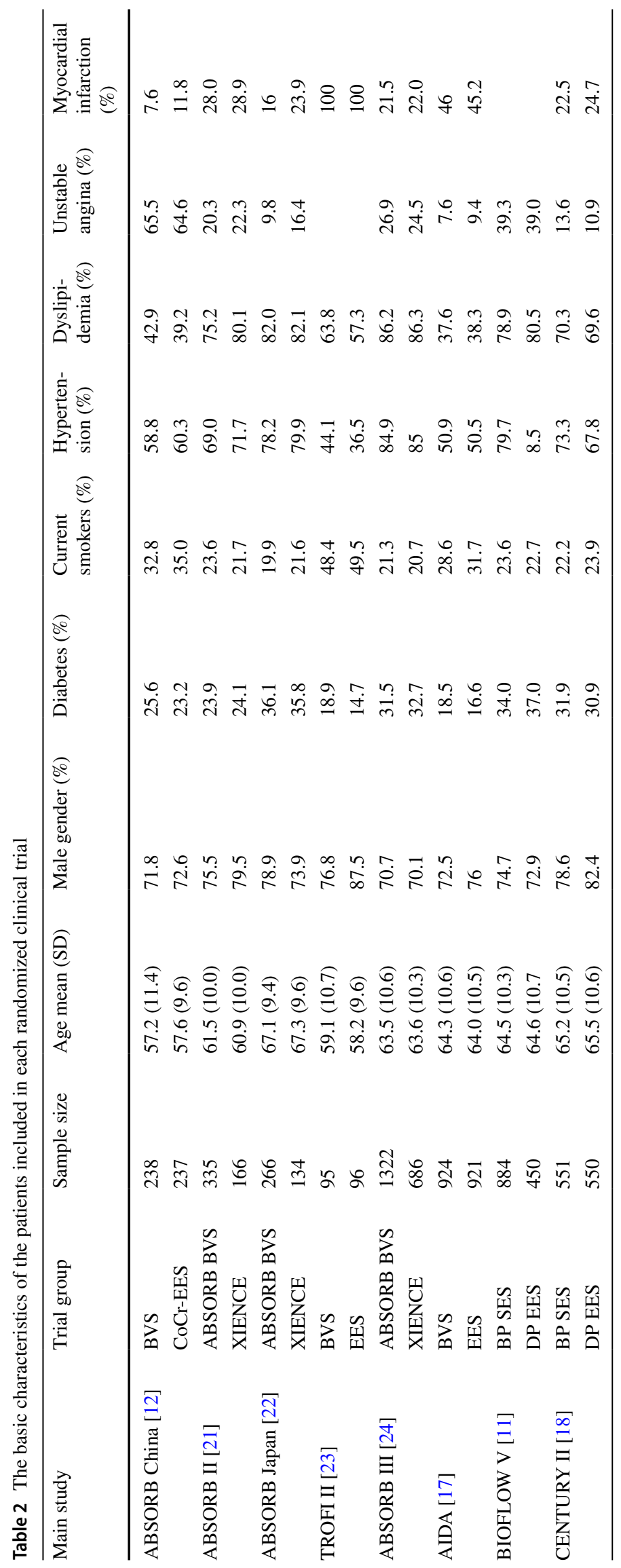


Table 3 The outcomes measured in the different examined studies

\begin{tabular}{|c|c|c|c|c|}
\hline Author & Two trial groups & Follow-up & Outcomes & Dual antiplatelet therapy \\
\hline $\mathrm{Xu} \mathrm{B}$ et al. [12] & BVS vs. CoCr-EES & $1-3$ years & 1/0: 1 & $20.8 \%$ vs. $18.2 \%, p=0.49$ \\
\hline Chevalier B et al. [13] & ABSORB BVS vs. XIENCE & $>1$ year & 0.6/0:0.554 & $36 \%$ vs. $34 \%$ \\
\hline Kereiakes DJ et al. [14] & ABSORB BVS vs. XIENCE & $\begin{array}{l}5 \text { years } \\
0-3 \text { years } \\
3-5 \text { years }\end{array}$ & $\begin{array}{l}2.5 \% / 1.1 \%: 0.03 \\
2.4 \% / 0.7 \%: 0.01 \\
0.1 \% / 0.3 \%: 0.24\end{array}$ & Similar in the two groups \\
\hline Onuma Y et al. [15] & ABSORB BVS vs. XIENCE & $\begin{array}{l}1-2 \text { years } \\
>2 \text { years }\end{array}$ & $3.8 \% / 1.6 \%: 0.34$ & Half of the patients \\
\hline Kozuma $\mathrm{K}$ et al. [16] & ABSORB BVS vs. XIENCE & 5 years & $\begin{array}{l}3.1 \% / 1.5 \%: 0.51 \\
1.6 \% / 0: 0.31\end{array}$ & $29.8 \%$ vs. $26.9 \%$ \\
\hline Wykrzykowska JJ et al. [17] & BVS vs. EES & $1-3$ years & $1.08 \% / 0.21 \%: 0.02$ & 1 year: $89.5 \%$ vs. $89.1 \%$ \\
\hline Kandzari DE et al. [11] & BP SES vs. DP EES & $1-2$ years & 0/0.7\%: 0.038 & $45.6 \%$ vs. $45.1 \%$ \\
\hline Kandzari DE et al. [10] & BP SES vs. DP EES & $1-3$ years & $0 / 0.5 \%: 0.11$ & $1-3$ years: $35.5 \%$ vs. $36.3 \%$ \\
\hline Wijns W et al. [18] & BP SES vs. DP EES & 5 years & $0.2 \% / 0.2 \%: 0.99$ & $15.7 \%$ vs. $13.6 \%: 0.36$ \\
\hline Katagiri Y et al. [19] & BVS vs. EES & 3 years & 1.1\%/1: 0.98 & $10.8 \%$ vs. $6.3 \%$ \\
\hline Wu Y et al. [20] & XINSORB vs. SES & $1-3$ years & $0.5 \% / 0: \mathrm{NS}$ & $59.0 \%$ vs. $52.8 \%$ \\
\hline
\end{tabular}

\section{Discussion}

The findings of this systematic review showed that the frequency of VLST was the same in the two groups in most of the investigated studies, and a significant difference was observed in this respect in only three RCTs.

The results of ABSORB III, which was one of the studies with a large sample size and long follow-up period, showed that over the 3 years of follow-up following PCI, the frequency of VLST was higher in the BVS group compared to the Xience group, and the HR obtained was 3.23 (1.25-8.30). In addition, in the 3-year follow-up, many clinical complications, including death, incidence of MI, and need for revascularization, were significantly higher in the BVS group. Yet, no significant difference was observed in clinical complications or VLST after 3 years and in the 3- to 5-year follow-up [14]. Based on the results of this study, the FDA issued a warning in 2017 on the use of BRSs and the need to comply with all the related guidelines and carried out negotiations with the stent manufacturer about conducting further experiments and studies [25]. Another study showing differences in the incidence of VLST was AIDA, where the incidence of acute as well as late and VL thrombosis was significantly higher in the BVS group. Moreover, among all the clinical complications, the incidence of MI was significantly higher in this group, although the two groups were not significantly different in terms of their death rate [17]. The important point in these two studies was their large sample size.

Despite these results, the results obtained in BIOFLOW V study showed the superiority of BP SES over DP EES, as no patient in the BRS group suffered ST in the 1- to 3-year follow-up, while VLST was reported in $0.7 \%$ of the cases in the Xience group. Meanwhile, the incidence of some clinical complications, including target vessel myocardial infarction, ischemia-driven target lesion revascularization, cardiac death or any myocardial infarction, major adverse clinical event composite, and ischemia-driven target vessel revascularization, was reportedly higher in the 3-year follow-up of the DP EES group compared to the BP SES group. By definition, VLST does not include cases of thrombosis for less than 1 year. Consequently, with regard to clinical complications, it is possible that complications that had occurred in less than 1 year were also included, and VLST cannot be compared to clinical complications in this respect, particularly given that although the number of patients with clinical complications was higher in the BP SES group, using the Kaplan-Meier rate at 3 years showed the superiority of BP SES over DP EES in the occurrence of clinical complications. This issue shows that the likelihood of thrombosis increases as stent is more absorbed over time, and for as long as the scaffold exists in the artery, it has a similar effect to non-absorbable stents in the arterial wall and the possibility of clinical complications remains increased. The lack of a significant difference in the incidence of acute, sub-acute, and late thrombosis in the two groups participating in this study probably confirms this point, which is also emphasized by the researchers of this paper [10].

Bioresorbable stents were produced in response to complications following implantation of stents with non-absorbable scaffolds. Studies have shown the increased likelihood of vascular damage following the implantation of BMSs. Hence, absorbable stents were produced with the pharmacological properties of DES to prevent vascular changes as their scaffold was absorbed. BMS-related complications were expected to substantially decrease with the production of DES; however, stent breakage and the annual complications of stent implantation persisted, and these complications 
appear to be caused by the metallic scaffold of stents [7]. Consequently, BRSs were designed and manufactured, and many studies were conducted on these stents using different methods, including clinical trials. Although these stents have been approved by the FDA, since BVSs remain in the vessels for about 3 years, further studies and long-term investigations on them appear necessary. One of the cases requiring long-term investigations was the incidence of VLST, which is currently being examined in different RCTs as well as registry and observational studies. Yet, given the longevity of these stents, only their 5-year effects have been assessed at most. The present study attempted to investigate the longterm complications of these stents by reviewing various RCTs, but as shown by the results, although the incidence of VLST was significantly higher in the DES group in AIDA and ABSORB III studies in the 1- to 3-year follow-ups, there was no significant difference between BRSs and DESs in the 5-year follow-ups.

Various meta-analyses of different studies have been performed to investigate the complications of BRSs. The results of one of the latest meta-analyses showed that in the followup of BVS complications, cardiac death and thrombosis over 1-year follow-ups were more prevalent with the use of these stents than DES. This meta-analysis had reviewed only ten RCTs published by 2018 on the 1-year complications of these stents, and based on its results, BVS was believed to not be as safe as DES in the 1-year follow-up. In their study, the results of ABSORB III and AIDA studies showed the greatest effectiveness in the incidence of BVS complications [26].

The results of a recently published meta-analysis of RCTs showed that compared to DES, BVS is less safe or effective. Their results showed that patients with BVS are exposed to target lesion failure and higher rates of VLST in a 3-year follow-up. In addition, although there is no significant difference between the groups in the risk of death, the likelihood of clinical complications such as MI and ischemia is higher in BVS than in DES. It should be noted that these results pertain to the first 3 years of the follow-up and might also include acute thrombosis and complications, but no significant difference was observed between these two stents in the 3- to 5-year follow-ups of stenting [27].

Even the latest guidelines recommended by the European Society of Cardiology (ESC) have paid particular attention to the increased incidence of thrombosis, clinical complications, and need for revascularization. Therefore, the ESC guideline does not recognize BVS as a safe and effective stent, and its use in PCIs has not been recommended [28].

It is important to note that BRS has a lifespan of almost 3 years [14], which probably means that the incidence of thrombosis will be the same after these stents are absorbed, and these stents could perhaps prove superior with longer follow-ups. Based on the results of the present study and the discussed meta-analyses, the scaffold of these stents may increase the incidence of thrombosis in the first 3 years after their insertion. It is important to note that even in BIOFLOW study, the incidence of clinical complications was significantly higher with these stents in the first 3 years when taking into account the KaplanMayer rate.

According to the results of the present study and other systematic review studies, in the first 3 years after insertion, the incidence of complications appears to be higher with BVS than DES, and when BVS is almost fully absorbed (over 3 to 5 years), the incidence of complications becomes almost the same in both groups. It is possible that the polymer used in these stents somehow causes increased thrombosis, and further pathological and cytological studies are thus essential. In addition, DESs may show greater complications than BVSs at longer follow-ups, but what seems to be almost certain is the rate of incidence of complications in the first 3 years after BVS insertion, which means that their use requires further investigations.

\section{Conclusion}

The RCTs conducted so far suggest that VLST and other clinical complications are higher with BRS than DES with steel scaffold. Therefore, interventionists should be very cautious in their use of BRSs and should only employ them when they are required by the standards. The FDA gave the same advice in 2017 and recommended that these stents only be used after the careful assessment of the approved criteria.

Author Contribution MS, HZ, RS, WW, and FS drafted the manuscript. MS and HZ performed the data collection. MS, HZ, and FS conceived and designed the study. All authors have read and approved the final version of the manuscript.

Funding Open Access funding provided by the IReL Consortium. Dr. Haroon Zafar is supported by Science Foundation Ireland (SFI) Technology Innovation Development Award (grant number: 18/TIDA/6017) and Irish Research Council New Foundations Grant 2020.

Data Availability Not applicable.

Code Availability Not applicable.

\section{Declarations}

Ethics Approval Not applicable.

Consent to Participate Not applicable.

Consent for Publication Not applicable. 
Competing Interests The authors declare no competing interests.

Open Access This article is licensed under a Creative Commons Attribution 4.0 International License, which permits use, sharing, adaptation, distribution and reproduction in any medium or format, as long as you give appropriate credit to the original author(s) and the source, provide a link to the Creative Commons licence, and indicate if changes were made. The images or other third party material in this article are included in the article's Creative Commons licence, unless indicated otherwise in a credit line to the material. If material is not included in the article's Creative Commons licence and your intended use is not permitted by statutory regulation or exceeds the permitted use, you will need to obtain permission directly from the copyright holder. To view a copy of this licence, visit http://creativecommons.org/licenses/by/4.0/.

\section{References}

1. Tomberli B, Mattesini A, Baldereschi GI, Di Mario C. A brief history of coronary artery stents. Rev Esp Cardiol (Engl Ed). 2018;71(5):312-9.

2. Yamaji K, Ueki Y, Souteyrand G, Daemen J, Wiebe J, $\mathrm{Nef} \mathrm{H}$, et al. Mechanisms of very late bioresorbable scaffold thrombosis: the INVEST registry. J Am Coll Cardiol. 2017;70(19):2330-44.

3. Kaliyadan A, Siu H, Fischman DL, Ruggiero NJ 2nd, Jasti B, Walinsky P, et al. "Very" very late stent thrombosis: acute myocardial infarction from drug-eluting stent thrombosis more than 5 years after implantation. J Invasive Cardiol. 2014;26(9):413-6.

4. Levine GN, Bates ER, Bittl JA, Brindis RG, Fihn SD, Fleisher LA, et al. 2016 ACC/AHA guideline focused update on duration of dual antiplatelet therapy in patients with coronary artery disease: a report of the American College of Cardiology/American Heart Association Task Force on Clinical Practice Guidelines: an update of the $2011 \mathrm{ACCF} / \mathrm{AHA} / \mathrm{SCAI}$ guideline for percutaneous coronary intervention, 2011 ACCF/AHA guideline for coronary artery bypass graft surgery, 2012 ACC/AHA/ACP/ AATS/PCNA/SCAI/STS guideline for the diagnosis and management of patients with stable ischemic heart disease, 2013 ACCF/AHA guideline for the management of ST-elevation myocardial infarction, 2014 AHA/ACC guideline for the management of patients with non-ST-elevation acute coronary syndromes, and 2014 ACC/AHA guideline on perioperative cardiovascular evaluation and management of patients undergoing noncardiac surgery. Circulation. 2016;134(10):e123-55.

5. Valgimigli M, Bueno H, Byrne RA, Collet JP, Costa F, Jeppsson A, et al. 2017 ESC focused update on dual antiplatelet therapy in coronary artery disease developed in collaboration with EACTS. Eur J Cardiothorac Surg. 2018;53(1):34-78.

6. Palmerini T, Bruno AG, Gilard M, Morice MC, Valgimigli M, Montalescot G, et al. Risk-benefit profile of longer-than-1year dual-antiplatelet therapy duration after drug-eluting stent implantation in relation to clinical presentation. Circ Cardiovasc Interv. 2019;12(3):e007541.

7. Bangalore S, Kumar S, Fusaro M, Amoroso N, Attubato MJ, Feit F, et al. Short- and long-term outcomes with drug-eluting and bare-metal coronary stents: a mixed-treatment comparison analysis of 117762 patient-years of follow-up from randomized trials. Circulation. 2012;125(23):2873-91.

8. Serruys PW, Garcia-Garcia HM, Onuma Y. From metallic cages to transient bioresorbable scaffolds: change in paradigm of coronary revascularization in the upcoming decade? Eur Heart J. 2012;33(1):16-25b.
9. Polimeni A, Anadol R, Münzel T, Indolfi C, De Rosa S, Gori T. Long-term outcome of bioresorbable vascular scaffolds for the treatment of coronary artery disease: a meta-analysis of RCTs. BMC Cardiovascular Disorders. 2017;17:147.

10. Kandzari DE, Koolen JJ, Doros G, Garcia-Garcia HM, Bennett J, Roguin A, et al. Ultrathin bioresorbable-polymer sirolimuseluting stents versus thin durable-polymer everolimus-eluting stents for coronary revascularization: 3-year outcomes from the randomized BIOFLOW V trial. JACC: Cardiovasc Interv. 2020;13(11):1343-53.

11. Kandzari DE, Koolen JJ, Doros G, Massaro JJ, Garcia-Garcia HM, Bennett J, et al. Ultrathin bioresorbable polymer sirolimuseluting stents versus thin durable polymer everolimus-eluting stents. J Am Coll Cardiol. 2018;72(25):3287-97.

12. Xu B, Yang Y, Han Y, Huo Y, Wang L, Qi X, et al. Comparison of everolimus-eluting bioresorbable vascular scaffolds and metallic stents: three-year clinical outcomes from the ABSORB China randomised trial. EuroIntervention. 2018;14(5):e554-61.

13. Chevalier B, Abizaid A, Carrié D, Frey N, Lutz M, WeberAlbers $\mathbf{J}$, et al. Clinical and angiographic outcomes with a novel radiopaque sirolimus-eluting bioresorbable vascular scaffold: the FANTOM II study. Circulation: Cardiovasc Interv. $2019 ; 12(6)$.

14. Kereiakes DJ, Ellis SG, Metzger DC, Caputo RP, Rizik DG, Teirstein PS, et al. Clinical outcomes before and after complete everolimus-eluting bioresorbable scaffold resorption: five-year follow-up from the ABSORB III trial. Circulation. 2019;140(23):1895-903.

15. Onuma Y, Sotomi Y, Shiomi H, Ozaki Y, Namiki A, Yasuda S, et al. Two-year clinical, angiographic, and serial optical coherence tomographic follow-up after implantation of an everolimus-eluting bioresorbable scaffold and an everolimus-eluting metallic stent: insights from the randomised ABSORB Japan trial. EuroIntervention. 2016;12(9):1090-101.

16. Kozuma K, Tanabe K, Hamazaki Y, Okamura T, Ando J, Ikari $\mathrm{Y}$, et al. Long-term outcomes of absorb bioresorbable vascular scaffold vs. everolimus-eluting metallic stent - a randomized comparison through 5 years in Japan -. Circ J. 2020;84(5):733-41.

17. Wykrzykowska JJ, Kraak RP, Hofma SH, van der Schaaf RJ, Arkenbout EK, IJsselmuiden AJ, et al. Bioresorbable scaffolds versus metallic stents in routine PCI. N Engl J Med. 2017;376(24):2319-28.

18. Wijns W, Valdes-Chavarri M, Richardt G, Moreno R, IniguezRomo A, Barbato E, et al. Long-term clinical outcomes after bioresorbable and permanent polymer drug-eluting stent implantation: final five-year results of the CENTURY II randomised clinical trial. EuroIntervention. 2018;14(3):e343-51.

19. Katagiri Y, Onuma Y, Asano T, Iniguez A, Jensen LO, Cequier À, et al. Three-year follow-up of the randomised comparison between an everolimus-eluting bioresorbable scaffold and a durable polymer everolimus-eluting metallic stent in patients with ST-segment elevation myocardial infarction (TROFI II trial). EuroIntervention. 2018;14(11):E1224-6.

20. Wu Y, Yao Z, Yin J, Chen J, Qian J, Shen L, et al. Three-year clinical outcomes of a sirolimus-eluting bioresorbable scaffold (XINSORB) and a metallic stent to treat coronary artery stenosis. Ann Transl Med. 2020;8(22):1489.

21. Chevalier B, Onuma Y, van Boven AJ, Piek JJ, Sabaté M, Helqvist $\mathrm{S}$, et al. Randomised comparison of a bioresorbable everolimuseluting scaffold with a metallic everolimus-eluting stent for ischaemic heart disease caused by de novo native coronary artery lesions: the 2-year clinical outcomes of the ABSORB II trial. EuroIntervention. 2016;12(9):1102-7.

22. Kimura T, Kozuma K, Tanabe K, Nakamura S, Yamane M, Muramatsu T, et al. A randomized trial evaluating everolimus-eluting Absorb bioresorbable scaffolds vs. everolimus-eluting metallic 
stents in patients with coronary artery disease: ABSORB Japan. Eur Heart J. 2015;36(47):3332-42.

23. Sabaté $\mathrm{M}$, Windecker $\mathrm{S}$, Iñiguez $\mathrm{A}$, Okkels-Jensen $\mathrm{L}$, Cequier A, Brugaletta S, et al. Everolimus-eluting bioresorbable stent vs. durable polymer everolimus-eluting metallic stent in patients with ST-segment elevation myocardial infarction: results of the randomized ABSORB ST-segment elevation myocardial infarction-TROFI II trial. Eur Heart J. 2015;37(3):229-40.

24. Ellis SG, Kereiakes DJ, Metzger DC, Caputo RP, Rizik DG, Teirstein PS, et al. Everolimus-eluting bioresorbable scaffolds for coronary artery disease. N Engl J Med. 2015;373(20):1905-15.

25. Maisel W. FDA Investigating increased rate of major adverse cardiac events observed in patients receiving Abbott Vascular's Absorb GT1 bioresorbable vascular scaffold (BVS) - letter to health care providers. U.S. Food and Drug Administration; 2017. Accessed 1 Mar 2022.
26. Ni L, Chen H, Luo Z, Yu Y. Bioresorbable vascular stents and drug-eluting stents in treatment of coronary heart disease: a metaanalysis. J Cardiothorac Surg. 2020;15(1):26.

27. Ke J, Zhang H, Huang J, Lv P, Chen Y, Xu K, et al. Three-year outcomes of bioresorbable vascular scaffolds versus second-generation drug-eluting stents: meta-analysis of randomized trials. Medicine (Baltimore). 2020;99(31):e21554.

28. Neumann FJ, Sousa-Uva M, Ahlsson A, Alfonso F, Banning AP, Benedetto U, et al. 2018 ESC/EACTS guidelines on myocardial revascularization. EuroIntervention. 2019;14(14):1435-534.

Publisher's Note Springer Nature remains neutral with regard to jurisdictional claims in published maps and institutional affiliations. 